Check for updates

Cite this: RSC Adv., 2019, 9, 19905

Received 10th January 2019

Accepted 17th June 2019

DOI: $10.1039 / c 9 r a 00228 f$

rsc.li/rsc-advances

\section{Advanced chemical stability diagrams to predict the formation of complex zinc compounds in a chloride environment $\uparrow$}

\begin{abstract}
M. E. McMahon, (D) R. J. Santucci, Jr and J. R. Scully
A chemical stability map is advanced by incorporating ion complexation, solubility, and chemical trajectories to predict $\mathrm{ZnO}, \mathrm{Zn}(\mathrm{OH})_{2}, \mathrm{ZnCO}_{3}, \mathrm{ZnCl}_{2}, \mathrm{Zn}_{5}\left(\mathrm{CO}_{3}\right)_{2}(\mathrm{OH})_{6}$, and $\mathrm{Zn}_{5}(\mathrm{OH})_{8} \mathrm{Cl}_{2} \cdot \mathrm{H}_{2} \mathrm{O}$ precipitation as a function of the total $\mathrm{Zn}$ content and $\mathrm{pH}$ of an $\mathrm{NaCl}$ solution. These calculations demonstrate equilibrium stability of solid $\mathrm{Zn}$ products often not considered while tracking the consumed and produced aqueous $\mathrm{Zn}$ ion species concentrations through chemical trajectories. The effect of $\mathrm{Cl}$-based ligand formation is incorporated into these stability predictions, enabling enhanced appreciation for the local corrosion conditions experienced at the $\mathrm{Zn}$ surface in chloride-containing environments. Additionally, the complexation of $\mathrm{Cl}^{-}$with $\mathrm{Zn}^{2+}$ is demonstrated to compete with the formation of solid phases, making precipitation more difficult. The present work also extends the chemical stability diagram derivations by incorporating a Gibbs-Thompson curvature relation to predict the effect of nanoscale precipitate phase formation on species solubility. These thermodynamic predictions correlate well with experimental results for $\mathrm{Zn}$ corrosion in full and alternate $\mathrm{NaCl}$ immersion, and have far-reaching utility in a variety of fields requiring nanoscale, semiconductor, and/or structural materials.
\end{abstract}

\section{Introduction}

Chemical stability predictions inform decisions in the corrosion engineering, chemical engineering, geology, soil science, energy, and biomedical fields. These technological fields increasingly demand the accurate understanding of chemical system progression in increasingly complex conditions. ${ }^{1-5}$ Classical thermodynamic predictions of metal stability, environmental degradation, and eventual corrosion product formation have undergone extensive experimental verification since Marcel Pourbaix's original derivation of $E-\mathrm{pH}$ (chemical stability) diagrams,,$^{2-7}$ however little work exists which actively aims to further develop Pourbaix's prediction methods. Recent work by Santucci et al. ${ }^{8}$ added to Pourbaix's chemical stability diagram method by developing chemical trajectory expressions which track the progression of available ion content in the global system with respect to $\mathrm{pH}$. The equilibrium metal (M) ion concentration $\left(\left[\mathrm{M}^{n+}\right]\right)$ and $\mathrm{pH}$ conditions necessary for $\mathrm{M}^{-}$ compound formation, as well as the changes in those conditions upon dissolution of the M-compound were graphically depicted in these improved chemical stability diagrams. The ionic concentration and $\mathrm{pH}$ trajectory trends were validated

Center for Electrochemical Science and Engineering, Department of Materials Science and Engineering, University of Virginia, Charlottesville, VA 22904, USA. E-mail: mm5kn@virginia.edu

$\dagger$ Electronic supplementary information (ESI) available. See DOI: $10.1039 / \mathrm{c} 9 \mathrm{ra} 00228 \mathrm{f}$ through analysis of the work of Plagemann et al., ${ }^{9}$ Lin et al., ${ }^{10}$ and $\mathrm{Xu}$ et al. ${ }^{11}$ concerning previously published yet not fully explained experimental findings, wherein customized chemical stability diagrams produced thermodynamic predictions that answered open questions remaining from the interpretation of purely empirical experimental results. ${ }^{8}$ However, these analyses required equilibrium stability calculation for relatively simple oxidation products whose precipitation could be predicted based on known chemical potentials. More complex corroding systems that have considerable engineering relevance have yet to be fully assessed through chemical stability prediction, as the necessary chemical potential data for such systems are not necessarily known. Thus, these methods must be expanded in breadth, complexity, and accuracy.

One element of increasing societal importance for materials science and engineering is zinc ( $\mathrm{Zn}$ ), which has been historically used in the design of brass alloys and for sacrificial corrosion protection. Corrosion in the $\mathrm{Zn}$ system has been thoroughly studied due to the importance of this metal for cathodic protection of steel, ${ }^{12}$ however formation of many typical and important $\mathrm{Zn}$ corrosion products are only qualitatively understood due to the complexity of their makeup. ${ }^{13}$ Today, $\mathrm{Zn}$ is also used in a wider variety of applications such as hazard management, biomedical applications such as drug delivery and antibiotics, as well as in electronics and data storage..$^{14-20}$ Depending on the application, either metallic $\mathrm{Zn}$ or a specific Zn corrosion product may be desired, for which the development of accurate stability/precipitation prediction methods 
would be beneficial and may inform product development for long-term use.

The complex makeup of many of the zinc compounds requires advancements in the derivation of expressions which track the evolution of total $\mathrm{Zn}$ concentration $\left([\mathrm{Zn}]_{\mathrm{Tot}}\right)$ in tandem with $\mathrm{pH}$ as these compounds react electrochemically to achieve equilibrium in the aqueous phase. Complexities arise due to proton transfer reactions (as with $\mathrm{Zn}^{2+}+\mathrm{OH}^{-}$and $\mathrm{CO}_{3}{ }^{2-}+\mathrm{H}^{+}$) and complexation reactions (as with $\mathrm{Zn}^{2+}+\mathrm{Cl}^{-}$). Therefore, the present work will quantify and predict corrosion product formation within the Zn system through thermodynamicallyderived chemical stability diagrams based on known solubility constants that have not been broadly considered. ${ }^{21}$ The derivation will include complexation effects due to chloride, hydroxide, and carbonate species as a function of bulk chemistry. Lastly, surface effects due to precipitated solid phase curvature will be incorporated into the method through utilizing a Gibbs-Thompson relation, which will predict the required conditions for spherical $\mathrm{ZnO}$ nanoparticle formation as a function of radius.

\section{Theory/calculations}

This work utilized recently developed solubility relations ${ }^{21}$ to derive chemical stability diagrams that encompass the spectrum of experimentally observed $\mathrm{Zn}$ corrosion products that form in non-sulfate-containing marine environment. These corrosion products include zincite $(\mathrm{ZnO})$, wulfingite $\left(\mathrm{Zn}(\mathrm{OH})_{2}\right.$, (amorphous as well as epsilon phase)), smithsonite $\left(\mathrm{ZnCO}_{3}\right)$, zinc chloride $\left(\mathrm{ZnCl}_{2}\right)$, simonkolleite $\left(\mathrm{Zn}_{5}(\mathrm{OH})_{8} \mathrm{Cl}_{2} \cdot \mathrm{H}_{2} \mathrm{O}\right)$, and zinc hydroxycarbonate $\left(\mathrm{Zn}_{5}\left(\mathrm{CO}_{3}\right)_{2}(\mathrm{OH})_{6}\right)^{12,13}$ Previous work demonstrated the utility of chemical stability diagrams when derived based on thermodynamic chemical potential data, which enabled the stability prediction of relatively simple reaction products such as $\mathrm{Mg}(\mathrm{OH})_{2}$ or $\mathrm{Li}_{2} \mathrm{CO}_{3}{ }^{8,22}$ In the $\mathrm{Zn}$ system, however, the presence of complex corrosion products such as simonkolleite and zinc hydroxycarbonate require an expansion on the previously demonstrated methods, as the chemical potentials for these complex products are not known or easily determined. ${ }^{12}$ It is worth noting that the present framework necessitates the use of molarity in the prediction of these complex $\mathrm{Zn}$ compounds, thus activity is not utilized in these thermodynamic equilibrium calculations. Utilizing molarity is of principal importance to allow for the tandem evaluation of the equilibrium boundary lines with the chemical dissolution trajectories. Previous work has shown that activity approaches unity in pure $\mathrm{NaCl}$ at concentrations increasingly less than or increasingly greater than $1 \mathrm{M}$ (with higher concentration actually reaching unity at saturation) (see ESI, $\dagger$ where the reproduced data being mentioned apply only to the case of pure $\mathrm{NaCl}) .{ }^{23}$ It is noteworthy that the $\mathrm{Zn}$ activity coefficients will vary in magnitude as a function of saline concentration between different aqueous environments, or if different ionic species are introduced into a given environment, and that specific $\mathrm{Zn}$ ionic complexes will exhibit different activities from one another in these scenarios. For mathematical purposes as well as the availability of required thermodynamic data, the present calculations necessarily assume pure $\mathrm{NaCl}+\mathrm{H}_{2} \mathrm{O}+$ $\mathrm{XCO}_{3}$ conditions, thus these results may be affected by the introduction of pollutants, foreign ionic species, etc. The $0.06 \mathrm{M}$ $\mathrm{NaCl}$ case analyzed here is the most likely to demonstrate calculation error based on known trends in activity in pure $\mathrm{NaCl}$ (see ESI $\dagger$ ), ${ }^{23}$ so this concentration was chosen for experimental validation, which will be detailed in an ensuing section.

\subsection{Construction of equilibrium chemical stability boundaries: bulk formation}

Baseline thermodynamic predictions in the present work neglected $\mathrm{Cl}^{-}$complexation effects, and so the calculation of each aqueous $\mathrm{Zn}$ ion's stability was necessary. The chosen environment was $\mathrm{NaCl}$, though other $\mathrm{Cl}^{-}$environments may also be considered. In cases where the cation is simple and has the same charge and/or affinity for complexation with $\mathrm{OH}^{-}$and $\mathrm{Cl}^{-}$, such as for $\mathrm{KCl}$, the results of these thermodynamic predictions will be the same until the solubility limit is reached for the less soluble salt. When the cation has greater charge and increased affinity for complexation, the predictions will differ from the $\mathrm{NaCl}$ scenario due to potential effects on the available free $\left[\mathrm{Cl}^{-}\right]$, as well as effects on the activities of surrounding species. Lange's Handbook of Chemistry provided stability constant values for the range of $\mathrm{Zn}$ ion species present in chloride-based, non-sulfate-containing saline environment. ${ }^{22}$ These data were utilized to create predominance diagrams for the $\mathrm{Zn}$ system, which demonstrated that three zones of ion predominance generally occur: $\mathrm{Zn}^{2+}(\mathrm{pH} 9.0$ and lower), $\mathrm{Zn}(\mathrm{OH})_{2}^{0}$ (pH 9.0 to $\mathrm{pH} 13.0$ ), and $\mathrm{Zn}(\mathrm{OH})_{4}{ }^{2-}$ (pH 13.0 and higher). ${ }^{6,12,22}$ Zinc predominance diagrams are common in the literature, especially when considering nanoparticle formulation, and are useful to determine available ion content within an electrochemical system as a function of $\mathrm{pH}^{24-26}$ These predominance results based on the Lange constants, which demonstrated $\mathrm{Zn}(\mathrm{OH})_{2}^{0}$ stability in the central $\mathrm{pH}$ region, were compared with previous work by Pourbaix, which computed a different set of aqueous $\mathrm{Zn}$ ions thought at the time to be dominant $\left(\mathrm{HZnO}_{2}{ }^{-}\right.$was most stable in the central $\mathrm{pH}$ region). ${ }^{6}$ These comparisons showed good correlation between the models, and demonstrated that, with self-consistent use of a given thermodynamic database, use of a certain ion for rederivation of stability products $\left(K_{\mathrm{sp}}\right)$ is not necessary to yield consistent predictions. Corrosion product reactions were then rederived with respect to $\mathrm{Zn}^{2+}, \mathrm{Zn}(\mathrm{OH})_{3}{ }^{-}$(chosen to enable the stability prediction of $\left.\mathrm{Zn}(\mathrm{OH})_{2}(\mathrm{~s})\right)$, and $\mathrm{Zn}(\mathrm{OH})_{4}{ }^{2-}$, creating three reactions and three $K_{\mathrm{sp}}$ values for each corrosion product which, when summed together, produce each equilibrium compound stability boundary line across the entire $\mathrm{pH}$ range (for situations where ion complexation effects due to $\mathrm{Cl}^{-}$are not considered). These $K_{\mathrm{sp}}$ values are shown with respect to each predominant ion in Table 1. For example, in the case of the amorphous $\mathrm{Zn}(\mathrm{OH})_{2}$ reaction equilibrium can be established through the following routes:

$$
\text { (Acidic) } \mathrm{Zn}(\mathrm{OH})_{2}(\mathrm{~s})=\mathrm{Zn}^{2+}(\mathrm{aq})+2 \mathrm{OH}^{-}(\mathrm{aq})
$$

(Near-neutral) $\mathrm{Zn}(\mathrm{OH})_{2}(\mathrm{~s})+\mathrm{OH}^{-}(\mathrm{aq})=\mathrm{Zn}(\mathrm{OH})_{3}{ }^{-}(\mathrm{aq})$ 
Table $1 \mathrm{Zn}$-based solid corrosion product equilibrium stability constants, $K_{\mathrm{sp}}$, and formation ratio with respect to predominance zone. $a=\#$ of available $\mathrm{Zn}$ cations required, $b=\#$ of available $\mathrm{OH}^{-}$species required, and $c=\#$ of $\mathrm{CO}_{3}{ }^{2-}$ species required for corrosion product formation. $K_{\mathrm{sp}}$ values are determined with respect to the dissolution of the compound to $\mathrm{Zn}^{2+}, \mathrm{Cl}^{-}, \mathrm{CO}_{3}^{2-}$, and $\mathrm{OH}^{-}$

\begin{tabular}{|c|c|c|c|c|c|}
\hline \multirow[b]{2}{*}{ Corrosion product } & & \multicolumn{3}{|c|}{$\begin{array}{l}\log \left(\text { solubility product }\left(K_{\mathrm{sp}}\right)\right) \text { for each ion } \\
\text { predominance zone }\end{array}$} & \multirow{2}{*}{$\begin{array}{l}\text { Species formation } \\
\text { ratio } \\
\mathrm{a}: b: \mathrm{c}\end{array}$} \\
\hline & & $\mathrm{Zn}^{2+}$ & $\mathrm{Zn}(\mathrm{OH})_{3}^{-}$ & $\mathrm{Zn}(\mathrm{OH})_{2}{ }^{2-}$ & \\
\hline $\mathrm{ZnO}$ & Zincite & -16.65 & -2.51 & 1.01 & $1: 2: 0$ \\
\hline $\mathrm{Zn}(\mathrm{OH})_{2}$ (amorphous) & Wulfingite (am) & -15.42 & -1.28 & -2.24 & $1: 2: 0$ \\
\hline $\mathrm{Zn}(\mathrm{OH})_{2}$ (epsilon) & Wulfingite $(\varepsilon)$ & -17.04 & -2.90 & -1.62 & $1: 2: 0$ \\
\hline $\mathrm{Zn}_{5}(\mathrm{OH})_{8} \mathrm{Cl}_{2} \cdot \mathrm{H}_{2} \mathrm{O}$ & Simonkolleite & -73.80 & -3.10 & 14.50 & $5: 8: 0$ \\
\hline
\end{tabular}

(Alkaline) $\mathrm{Zn}(\mathrm{OH})_{2}(\mathrm{~s})+2 \mathrm{OH}^{-}(\mathrm{aq})=\mathrm{Zn}(\mathrm{OH})_{4}{ }^{2-}(\mathrm{aq})$

Utilizing these reactions, the solubility relation can be determined based on the $K_{\mathrm{sp}}$ constants in Table 1, such as for eqn (1):

$$
\log \left(K_{\mathrm{sp}}\right)=\log \left(\frac{\left(\mathrm{Zn}^{2+}\right)\left(\mathrm{OH}^{-}\right)^{2}}{\mathrm{Zn}(\mathrm{OH})_{2}}\right)=-15.42
$$

Derivation of the three chemical stability equations, one with respect to each predominant aqueous $\mathrm{Zn}$ ion, when summed produced a solubility-based chemical stability diagram for $\mathrm{Zn}(\mathrm{OH})_{2}(\mathrm{am})$ based on the assumption that free dominant $\mathrm{Zn}_{\mathrm{aq}}$ ion availability is not limiting (always present in greater quantities than necessary for equilibrium corrosion product precipitation). The method of calculating these equilibria follows fundamental solubility relations, which can be found in previous work and elsewhere. ${ }^{8,22}$ The method of calculation and the exact solubility relations utilized to construct the chemical equilibrium diagrams are provided in detail in the ESI. $\dagger$

In the presence of complexing species such as chloride, however, the necessary $\mathrm{Zn}_{\mathrm{aq}}$ content required for unhindered corrosion product precipitation may not always exist, as these ligands compete for the use of this cation content through ligand formation (such as formation of $\mathrm{ZnCl}^{+}, \mathrm{ZnCl}_{3}{ }^{-}$, etc.). To account for this complexation competition, available, dominant $\mathrm{Zn}_{\mathrm{aq}}$ content was quantified for each ion predominance zone across the $\mathrm{pH}$ spectrum to quantify the "actual" solubility of each corrosion product. In this treatment, the actual solubility of $\mathrm{Zn}$-compounds was calculated with respect to free $\mathrm{Zn}^{2+}$ by determining the actual $\left[\mathrm{Zn}^{2+}\right]$ as a function of $\mathrm{pH}$ and $\left[\mathrm{Cl}^{-}\right]$. The specific stability constants, or $\beta$ values, shown in Table 2, were used to determine the ratio of each $\mathrm{Zn}$-based ion present in solution to the total aqueous $\mathrm{Zn}$ concentration, $\left[\mathrm{Zn}_{\text {Tot }}\right]$. The derivation of this aqueous $\mathrm{Zn}$ ion availability equation is provided in the ESI. $\dagger$ These equations were utilized to quantify the ratio of free $\mathrm{Zn}^{2+}$ ion content to the total aqueous $\mathrm{Zn}$ concentration for the $\mathrm{Zn}^{2+}$ ion. Since the $\mathrm{Zn}^{2+}$ requirement for corrosion product equilibrium was calculated from equations like eqn (4), the total $\mathrm{Zn}_{\mathrm{aq}}$ content required for corrosion product formation could be determined from this ratio.
Chemical stability diagrams were then reconstructed to incorporate complexation competition in this way, enabling these diagrams to predict bulk $\mathrm{Zn}$ corrosion product formation under more rigorous solubility conditions for the marine environment of interest.

\subsection{Construction of equilibrium chemical stability boundaries: nanoscale formation}

The size scale of the corrosion product formation was also evaluated by incorporating the Gibbs-Thompson curvature relation into the chemical stability trend equations. For this purpose, use of chemical potential was necessary instead of solubility, as has been practiced in previous work, ${ }^{6,8}$ which enabled the differentiation of the bulk chemical potential from the curvature-dependent chemical potential for the corrosion product of interest:

$$
\mu_{\text {curve }}(\text { convex })=\mu_{\text {bulk }}+\frac{2 \gamma \Omega}{r}
$$

where $\gamma=$ interfacial energy $\left(\mathrm{J} \mathrm{m}^{-2}\right), \Omega=$ molar volume $\left(\mathrm{m}^{3}\right.$ $\mathrm{mol}^{-1}$ ), and $r=$ radius of the nanosphere (m). As $\gamma$ and $\Omega$ can be experimentally and mathematically understood, the effect of curvature on corrosion product stability may then be assessed at the nanoscale. This derivation is conducted with respect to a spherical case, but these relations may be derived to consider

Table $2 \mathrm{Zn}$-based aqueous ion specific stability product constants, $\beta$, calculated based on formation from $\mathrm{Zn}^{2+}$

\begin{tabular}{lc}
\hline $\mathrm{Zn}-\mathrm{L}$ ion & $\log ($ stability product $(\beta))$, \\
species & $\beta=\frac{\left[\mathrm{Zn}(\mathrm{L})_{x}{ }^{2-x l}\right]}{\left[\mathrm{Zn}^{2+}\right]\left[\mathrm{L}^{l-}\right]^{x}}$ \\
\hline $\mathrm{Zn}(\mathrm{OH})^{+}$ & 4.40 \\
$\mathrm{Zn}(\mathrm{OH})_{2}^{0}$ & 11.30 \\
$\mathrm{Zn}(\mathrm{OH})_{3}{ }_{3}^{-}$ & 14.14 \\
$\mathrm{Zn}(\mathrm{OH})_{4}{ }^{2-}$ & 17.66 \\
$\mathrm{ZnCl}^{+}$ & 0.43 \\
$\mathrm{ZnCl}_{2}$ & 0.61 \\
$\mathrm{ZnCl}_{3}{ }^{-}$ & 0.53 \\
$\mathrm{ZnCl}_{4}{ }^{2-}$ & 0.20
\end{tabular}


more general curvature geometries also. In the case of the $\mathrm{ZnO}$ dissolution reaction in the $\mathrm{Zn}^{2+}$ predominance zone,

$$
\mathrm{ZnO}+\mathrm{H}_{2} \mathrm{O}=\mathrm{Zn}^{2+}+2 \mathrm{OH}^{-}
$$

for example, the incorporation of the surface curvature would affect the $\mathrm{ZnO}$ chemical potential component of the overall solubility relation:

$$
\begin{aligned}
& \log \left(\frac{\left[\mathrm{Zn}^{2+}\right]\left[\mathrm{OH}^{-}\right]^{2}}{1}\right) \\
& =\frac{-\left(\left(\mu_{\mathrm{Zn}^{2+}}+2 \mu_{\mathrm{OH}^{-}}\right)-\left(\mu_{\mathrm{H}_{2} \mathrm{O}}+\mu_{\text {bulk ZnO }}+\frac{2 \gamma \Omega}{r}\right)\right)}{2.303 R T}
\end{aligned}
$$

where $R$ is the ideal gas constant $\left(\mathrm{J} \mathrm{mol}^{-1} \mathrm{~K}^{-1}\right)$ and $T$ is temperature (K). The $\gamma_{\mathrm{ZnO}}$ value of $3.55 \mathrm{~J} \mathrm{~m}^{-2}$ was obtained from theoretical modeling literature (which does not incorporate the environment, but is a suitable baseline to evaluate trends in stability) and describes the assumedly relaxed lattice state on the (111) ZnO surface, ${ }^{27}$ which enabled the calculation of a nanoscale $\mathrm{ZnO}$ chemical stability diagram. Use of this relation enables the derivation of chemical stability based on both "actual" solubility and surface curvature to enable thermodynamic prediction of the $\mathrm{Zn}$ ion concentration and $\mathrm{pH}$ boundaries for $\mathrm{ZnO}$ nanostructure formation and dissolution.

\subsection{Construction of chemical trajectory trends}

The derivation of the chemical trajectory relations required unique expressions for each corrosion product or group of corrosion products having a specific and unique elemental ratio. To first quantify the ratio of produced cations and the corresponding $\mathrm{pH}$ change associated with the dissolution of each corrosion product, consider the general $\mathrm{Zn}$ reaction for a simple hydroxide:

$$
\mathrm{M}_{a}(\mathrm{OH})_{b}+n \mathrm{H}^{+}=a \mathrm{M}^{n+}+b \mathrm{H}_{2} \mathrm{O}
$$

where the desired cation $\left(\mathrm{M}^{n+}\right)$ to $\mathrm{H}^{+}$ratio is $a: n$ (the relationship between metal ion charge and number of hydrogen ions may require more sophisticated variable assignment in exceedingly complex reactions). Effects on chemical trajectory due to the presence of a $\mathrm{pH}$ buffer have been considered and quantified in previous work. ${ }^{8}$ After applying the previously developed trajectory expressions to quantify the $\left[\mathrm{M}^{n+}\right]$ change as a function of $\mathrm{pH}$ for the corroding system, ${ }^{8}$ the following general chemical trajectory equation is produced:

$$
\begin{aligned}
\log \left[\mathrm{M}^{n+}\right] & =\log \left(\left[\mathrm{M}^{n+}\right]_{\text {init }}+\frac{a}{b}\left[10^{-\mathrm{pH}_{\text {init }}}-10^{-\mathrm{pH}_{\text {inst }}}\right]\right. \\
& \left.+\frac{a}{b}\left[10^{\mathrm{pH}_{\text {inst }}-14}-10^{\mathrm{pH}_{\text {init }}-14}\right]\right)
\end{aligned}
$$

However, the effects of more complex corrosion product dissolution need to be assessed in the Zn system, in which exist complex elemental ratios that must be accounted for. For instance, take the simonkolleite $\left(\mathrm{Zn}_{5}(\mathrm{OH})_{8} \mathrm{Cl}_{2} \cdot \mathrm{H}_{2} \mathrm{O}\right)$ dissolution reaction:

$$
\mathrm{Zn}_{5} \mathrm{OH}_{8} \mathrm{Cl}_{2} \cdot \mathrm{H}_{2} \mathrm{O}=5 \mathrm{Zn}^{2+}+8 \mathrm{OH}^{-}+2 \mathrm{Cl}^{-}+\mathrm{H}_{2} \mathrm{O}
$$

In this reaction, the produced cation content must be tracked according to the change in $\mathrm{OH}^{-}$or $\mathrm{H}^{+}$concentration. During complexation competition, the available free $\mathrm{OH}^{-}$ content and its distribution between $\mathrm{Zn}(\mathrm{OH})^{+}$, $\mathrm{Zn}(\mathrm{OH})_{2}^{0}, \mathrm{Zn}(\mathrm{OH})_{3}{ }^{-}$, or $\mathrm{Zn}(\mathrm{OH})_{4}{ }^{2-}$ will be affected by $\mathrm{pH}$ (Table 2). For that purpose, the fraction of hydroxylation $\left(\mathrm{OH}^{-}\right.$ consumption to form aqueous OH-based complexes) that occurs for each released $\mathrm{M}^{n+}$ may be tracked as $f$ :

$$
f=\sum d\left[\mathrm{M}(\mathrm{OH})_{d}^{n-d}\right]_{d \in[1,4]}
$$

where $d$ is the required number of $\mathrm{OH}^{-}$consumed during hydroxylation and $n$ is the charge of the free metal ion. When the given reaction occurs, such as simonkolleite dissolution, $8 \mathrm{OH}^{-}$species are produced as well as $5 \mathrm{Zn}^{2+}$ species ( $b=8, a=5, a: b$ ratio $=5: 8)$. The $a: b$ ratio would quantify the chemical system progression ([Zn $\left.]_{\text {tot }}\right)$ across the $\mathrm{pH}$ range of an $\mathrm{M}^{n+}-\mathrm{pH}$ diagram without the complication of species complexation; however, the subsequent complexation of $\mathrm{OH}^{-}$species, according to the $f$ function reduces the effective increase in available $\mathrm{OH}^{-}$content as a function of $\mathrm{pH}$, requiring that eqn (11) incorporate such effects to become:

$$
\begin{aligned}
\log \left[\mathrm{M}^{n+}\right] & =\log \left(\left[\mathrm{M}^{n+}\right]_{\text {init }}+\frac{a}{b-a f}\left[10^{-\mathrm{pH}_{\text {init }}}-10^{-\mathrm{pH}_{\text {inst }}}\right]\right. \\
& \left.+\frac{a}{b-a f}\left[10^{\mathrm{pH}_{\text {inst }}-14}-10^{\mathrm{pH}_{\text {init }}-14}\right]\right)
\end{aligned}
$$

Furthermore, the presence of carbonate species must also be quantified to establish the proper trend, as the availability of $\mathrm{CO}_{3}{ }^{2-}$ is also influenced by $\mathrm{pH}$. The concentration of $5 \mathrm{mM}$ was chosen for accuracy to typical atmospheric concentrations. ${ }^{28}$ While not considered here, the dissolved $\mathrm{CO}_{3}{ }^{2-}$ concentration may vary with $\mathrm{pH}$ and $\mathrm{CO}_{2}$ partial pressure and is known to impact the precipitation of various $\mathrm{Zn}$ corrosion products. ${ }^{29}$ Consider the dissolution of $\mathrm{Zn}$ hydroxycarbonate:

$$
\mathrm{Zn}_{5}\left(\mathrm{CO}_{3}\right)_{2} \mathrm{OH}_{6}=5 \mathrm{Zn}^{2+}+2 \mathrm{CO}_{3}^{2-}+6 \mathrm{OH}^{-}
$$

For this reaction to occur, the availability of the $\mathrm{pH}$ dependent species $\mathrm{CO}_{3}{ }^{2-}$ is necessary, as can be understood through the following relation:

$$
\begin{aligned}
\mathrm{Zn}(\mathrm{OH})_{f}^{2-f}+\mathrm{H}_{F}\left(\mathrm{CO}_{3}\right)_{c}^{-(2-F)} & =\mathrm{Zn}^{2+}+f \mathrm{OH}^{-}+c \mathrm{CO}_{3}{ }^{2-} \\
& +\mathrm{FH}^{+}
\end{aligned}
$$

where $c$ is the required number of $\mathrm{CO}_{3}{ }^{2-}$ species. This combined reliance on hydroxyl and carbonate species availability produces the following chemical trajectory equation to quantify the progression of $\mathrm{pH}$ and $\left[\mathrm{M}^{+}\right]$dissolved in solution: 


$$
\begin{aligned}
\log \left[\mathrm{M}^{n+}\right] & =\log \left(\left[\mathrm{M}^{n+}\right]_{\text {init }}+\frac{a}{b+c F-a f}\left[10^{-\mathrm{pH}_{\text {init }}}-10^{-\mathrm{pH}_{\text {inst }}}\right]\right. \\
& +\frac{a}{b+c F-a f}\left[10^{\mathrm{pH}_{\text {inst }}-14}-10^{\mathrm{pH}_{\text {init }}-14}\right] \\
& \left.+\left[\frac{\left[\mathrm{CO}_{3}{ }^{2-}\right]_{\text {init }}}{b+c F-a f}\left(G_{\text {inst }}^{\mathrm{CO}_{3}{ }^{2-}}-G_{\text {init }}^{\mathrm{CO}_{3}{ }^{2-}}\right)\right]\right)
\end{aligned}
$$

where $G^{\mathrm{CO}_{3}{ }^{2-}}$ quantifies the fraction of available $\mathrm{CO}_{3}{ }^{2-}$ in a similar fashion as eqn (11). For the calculation of the remaining chemical trajectories necessary to describe the corroding $\mathrm{Zn}$ system, the $a: b: c$ ratio for each $\mathrm{Zn}$ corrosion product is included in Table 1. Together, these trend relations enable the tracking of the available aqueous $\mathrm{Zn}$ ion concentration from an initial $\mathrm{pH} /$ available $\mathrm{CO}_{3}{ }^{2-}$ condition in consideration $\mathrm{OH}^{-}$- and $\mathrm{Cl}^{-}$-based ligand formation.

\section{Experimental methods}

Titration testing was conducted in $0.06 \mathrm{M} \mathrm{NaCl}$ solution at the $\mathrm{Zn}^{2+}$ concentrations of $10^{-3} \mathrm{M}$ and $10^{-6} \mathrm{M}$ to assess the accuracy of the chemical stability diagram where the difference between activity and concentration would be highest (compared to the $5.45 \mathrm{M}[\mathrm{NaCl}]$ scenario). Experiments were conducted with actively stirred $10^{-3} / 10^{-6} \mathrm{M}\left[\mathrm{Zn}^{2+}\right], 0.06 \mathrm{M}[\mathrm{NaCl}]$ solution while actively measuring the $\mathrm{pH}$. Titrant made of the same solution plus several $\mathrm{mL}$ of $\mathrm{NaOH}$ to reach $\mathrm{pH}$ of approximately 13 (above the stable region of solid $\mathrm{Zn}$ corrosion product formation) was added in $25 \mu \mathrm{L}$ increments. Following 1 minute of mixing after each titration, the presence or absence of solid $\mathrm{Zn}$ corrosion product was noted, for comparison to thermodynamic predictions.

\section{Results}

\subsection{Ion predominance and chemical stability as a function of bulk environment}

To begin to develop a more inclusive chemical stability diagram for the $\mathrm{Zn}$ system, the regions and type of $\mathrm{Zn}$ ion species predominance must be understood based on the spectrum of $\mathrm{Zn}$ ions known to occur in a given solution. Consider a non-sulfatecontaining chloride environment where $\mathrm{Zn}^{2+}$ is provided by any dissolution process that may occur during corrosion, drug delivery, Zn-rich coating depletion, oxide degradation, etc. The pertinent ions are listed in Table 2. The state of chloride saturation at $5.45 \mathrm{M}$ concentration was first assessed to evaluate predominance, as shown in Fig. 1. These diagrams are marked by threshold $\mathrm{pH}$ values at which a transition in the dominant, aqueous $\mathrm{Zn}$ ion species occurs. At this high chloride content, the $\mathrm{ZnCl}_{4}{ }^{2-}$ ion dominates from $\mathrm{pH}-1.0$ to 9.8 followed by $\mathrm{Zn}(\mathrm{OH})_{2}^{0}$ dominating from $\mathrm{pH} 9.8$ to 10.9 , and lastly $\mathrm{Zn}(\mathrm{OH})_{4}{ }^{2-}$ dominates from $\mathrm{pH} 10.9$ to 16.0. Similar $\mathrm{Zn}$ ion predominance diagrams have been previously produced in the literature for corrosion analysis at various fixed $\left[\mathrm{Cl}^{-}\right]$or $\left[\mathrm{CO}_{3}{ }^{2-}\right]$, many of which utilize the program MedusaHydra. ${ }^{30-34}$ However, these predominance diagrams are often underutilized and are not typically used to produce even basic chemical stability diagrams. As shown on the right $y$-axis in Fig. 1, the coordination of the dominant hydroxide species increases with increasing overall amount of consumed hydroxyl ions (and increasingly alkaline $\mathrm{pH}$ ). To evaluate the effect of the chloride complexation further, ion predominance was calculated at the dilute condition of $0.06 \mathrm{M}$, as shown in Fig. 2 . In the substantially reduced presence of $\mathrm{Cl}^{-}$the $\mathrm{Zn}^{2+}$ ion now dominates in the acidic region to a $\mathrm{pH}$ of 8.3. However, the neutral and alkaline regions remain unchanged, as transition between these aqueous ion predominance regions remains at a $\mathrm{pH}$ of 10.9 and both the $\mathrm{Zn}(\mathrm{OH})_{2}^{0}$ and $\mathrm{Zn}(\mathrm{OH})_{4}{ }^{2-}$ continue to dominate (Fig. 2). As can be

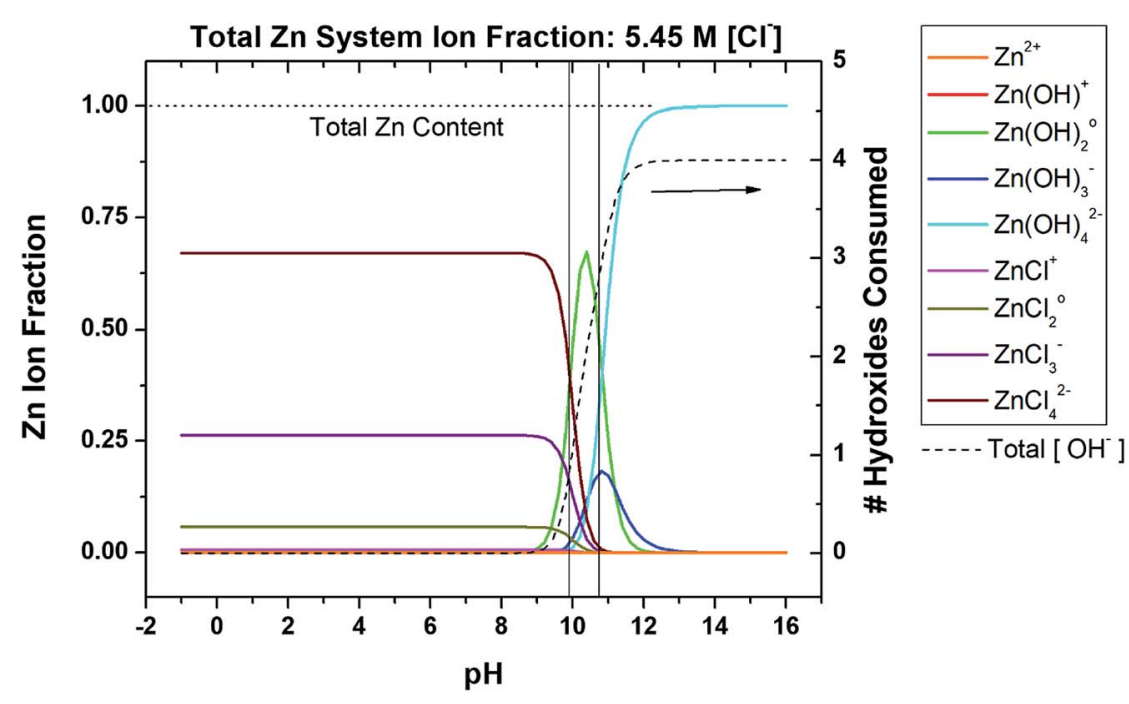

Fig. 1 Speciation diagram depicting the fractional distribution of various $\mathrm{Zn}$-based species as a function of $\mathrm{pH}$ for a given ligand concentration, in

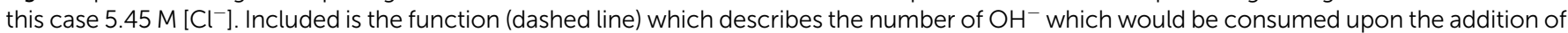
$\mathrm{Zn}^{2+}$ to the system, as a function of $\mathrm{pH}$. Transition points are marked by vertical black lines where the dominant aqueous $\mathrm{Zn}$ ion identity changes. This system neglects carbonates. 


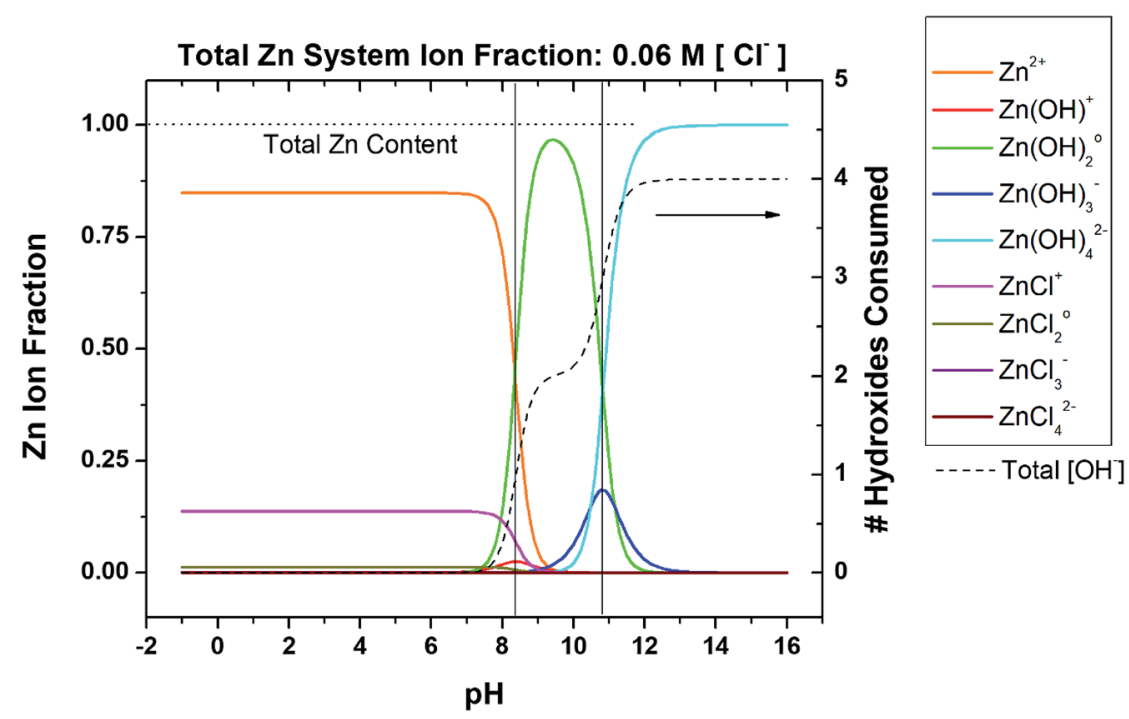

Fig. 2 Speciation diagram depicting the fractional distribution of various $\mathrm{Zn}$-based species as a function of pH for a given ligand concentration, in this case $0.06 \mathrm{M}^{\mathrm{Cl}^{-}}$. Included is the function (dashed line) which describes the number of $\mathrm{OH}^{-}$which would be consumed upon the addition of $\mathrm{Zn}^{2+}$ to the system, as a function of $\mathrm{pH}$. Transition points are marked by vertical black lines where the dominant aqueous $\mathrm{Zn}$ ion identity changes. This system neglects carbonates.

seen in the total hydroxyl consumption, the chloride content does have some measurable impact on the hydroxide formation at neutral $\mathrm{pH}$. As the more dilute conditions are common and chloride concentrations of approximately $2 \mathrm{M}$ are necessary before the $\mathrm{Zn}^{2+}$ ion no longer dominates in the acidic region, the predominant ions pertinent to the dilute scenario will be mainly considered for recalculation of corrosion product solubility relations to derive the chemical stability diagrams.

As a baseline, the $\mathrm{Zn}$ chemical stability diagram for saturated chloride conditions (5.45 M) was first developed neglecting $\mathrm{Cl}^{-}$ complexation effects (no limitation on available $\mathrm{Zn}_{\mathrm{aq}}$ content), as shown in Fig. 3 zoomed in to focus on the key pH range of 3.0

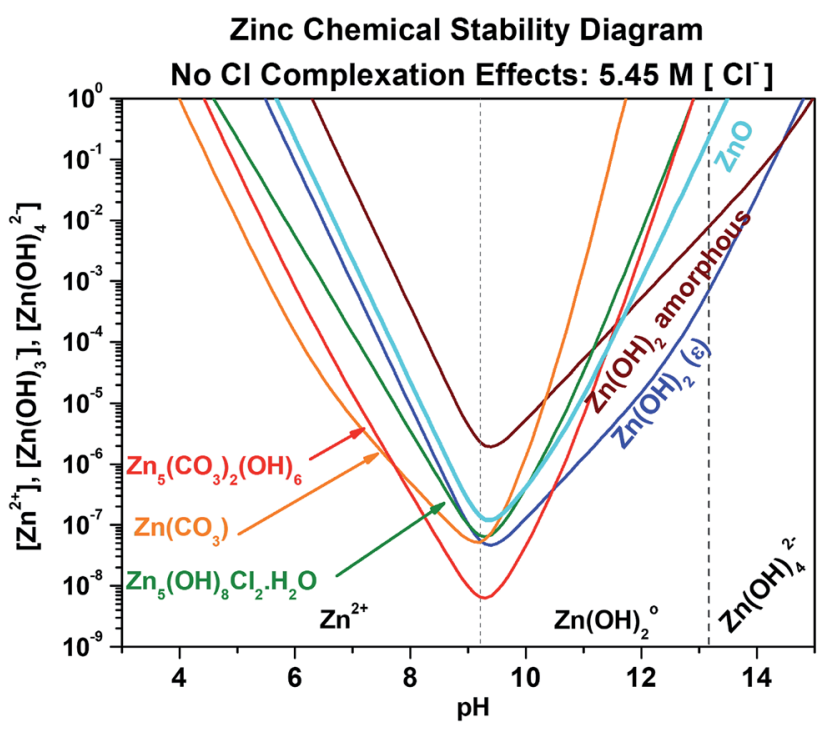

Fig. 3 Chemical stability diagram for the $\mathrm{Zn}$-water system. Relevant species are given for exposure in $\mathrm{Cl}^{-}(5.45 \mathrm{M})$ and $\mathrm{CO}_{3}{ }^{2-}(5.00 \mathrm{mM})$ containing environment. This diagram does not include the effect of ligand complexation due to the presence of $\mathrm{Cl}^{-}$. to 15.0. The exact chemical reactions necessary to construct Fig. 3, as well as the chemical stability diagrams to follow, can be found in the ESI. $\dagger$ Analyses of solid $\mathrm{Zn}$ corrosion product stability with respect to $\mathrm{pH}$ are present in the literature for simple $\mathrm{Zn}$-based corrosion products, but not for complex products such as $\mathrm{Zn}_{5}\left(\mathrm{CO}_{3}\right)_{2}(\mathrm{OH})_{8}$ and $\mathrm{Zn}_{5}(\mathrm{OH})_{8} \mathrm{Cl}_{2} \cdot \mathrm{H}_{2} \mathrm{O}{ }^{6,35}$ At these high chloride concentrations for a fixed dissolved carbonate content of $5 \mathrm{mM}, \mathrm{ZnCO}_{3}$ is the most readily formed corrosion product from $\mathrm{pH} 4.0$ to 7.8 , followed by $\mathrm{Zn}_{5}\left(\mathrm{CO}_{3}\right)_{2}(-$ $\mathrm{OH})_{8}$ from a pH of 7.8 to 10.8 , and lastly $\mathrm{Zn}(\mathrm{OH})_{2}$ (epsilon) from $\mathrm{pH} 10.2$ to 15.0 . These corrosion products require small $\mathrm{Zn}$ concentrations to form under these conditions, with the lowest requirement being approximately $8 \times 10^{-9} \mathrm{M}$ and $6 \times 10^{-8} \mathrm{M}$ $\mathrm{Zn}_{\mathrm{aq}}$ for $\mathrm{Zn}_{5}\left(\mathrm{CO}_{3}\right)_{2}(\mathrm{OH})_{8}$ and $\mathrm{Zn}(\mathrm{OH})_{2} / \mathrm{ZnCO}_{3}$ at $\mathrm{pH}$ 9.2, respectively. However, the condition of plentiful free $\mathrm{Zn}^{2+}$ content for corrosion product formation is unlikely, and free $\mathrm{Zn}^{2+}$ ion limited conditions must be quantified to more accurately predict corrosion product formation.

\subsection{Chemical stability as a function of bulk environment and complexation competition}

For the same saturated chloride $(5.45 \mathrm{M})$ condition, the $\mathrm{Zn}$ chemical stability diagram was then recalculated to include the effects of ion complexation, as shown in Fig. 4. Also included in Fig. 4 are the chemical trajectories $\left(\mathrm{M}^{n+}, \mathrm{pH}\right)$ to track the $\left[\mathrm{Zn}_{\text {Tot }}\right]$ progression of the system from an initial $\mathrm{pH}$ of 7 if $\mathrm{Zn}^{2+}$ were added to the solution via dissolution of the various compounds. Separate trajectory lines are necessary for each elemental ratio required to form the associated corrosion products (Table 1), thus the line color for the trajectories matches that of the associated corrosion product equilibrium stability line. For example, the orange chemical trajectory corresponds to the orange equilibrium chemical stability curve for $\mathrm{ZnCO}_{3}$, which has the unique $a: b: c$ of $1: 0: 1$ (Table 1 ). A unique case exists 


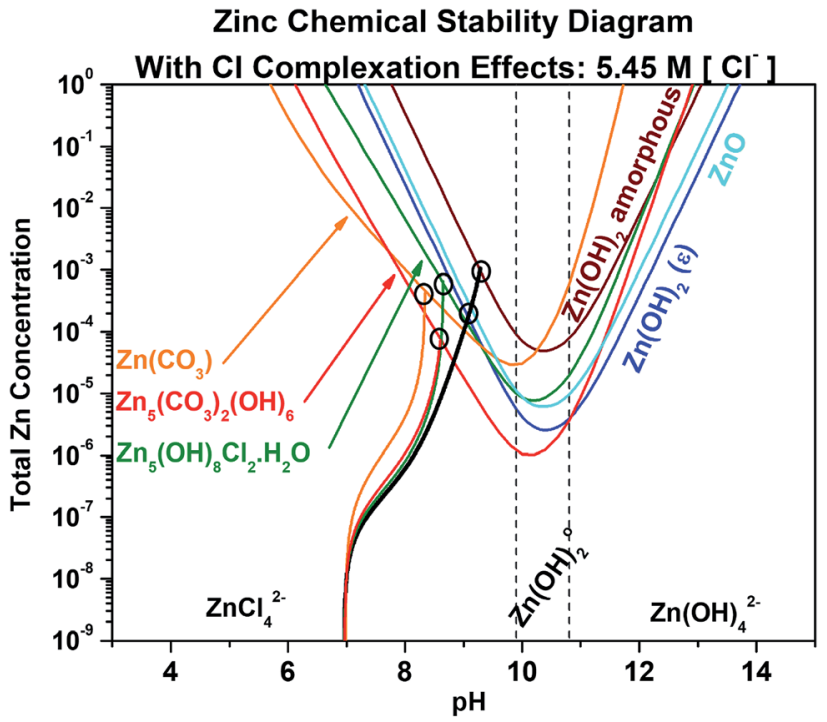

Fig. 4 Chemical stability diagram for the $\mathrm{Zn}$-water system. Relevant species are given for exposure in $\mathrm{C} \mathrm{Cl}^{-}(5.45 \mathrm{M})$ and $\mathrm{CO}_{3}{ }^{2-}(5.00 \mathrm{mM})$ containing environment. This diagram includes the effect of ligand complexation with $\mathrm{Cl}^{-}$on the stability of the zinc compounds. Included are chemical dissolution trajectories which describe how the solution chemistry progresses after assuming some initial condition $\left(\mathrm{pH}=7,\left[\mathrm{Zn}_{\text {Tot }}\right]=10^{-8}\right)$ to a final equilibrium condition (where the trajectory line intersects an equilibrium line). The trajectory line color matches that of the compound being tracked with respect to concentration and $\mathrm{pH}$ (black corresponds to the trajectory line involving both $\mathrm{Zn}(\mathrm{OH})_{2}$ and $\mathrm{ZnO}$ due to the expense of their trajectory being the same (Table 1)). Note the incorporation of ligand complexation effects due to the presence of $\mathrm{Cl}^{-}$.

for $\mathrm{Zn}(\mathrm{OH})_{2}$ and $\mathrm{ZnO}$, since both have $a: b: c$ of $1: 2: 0$ (Table 1), thus the single chemical trajectory associated with the chemical stability curves for $\mathrm{Zn}(\mathrm{OH})_{2}$ and $\mathrm{ZnO}$ is shown in black. The point of intersection between these chemical trajectories and the relevant equilibrium stability line has been circled to indicate the total aqueous $\mathrm{Zn}$ concentration and $\mathrm{pH}$ required for equilibration of each corrosion product. It is recognized that the equilibrium conditions may be met for the formation of a more stable compound upon the dissolution of a less stable compound, resulting in compound transformation over time. As can be readily observed in Fig. 4, the inclusion of complexation effects due to $\mathrm{Cl}^{-}$and $\mathrm{OH}^{-}$on corrosion product stability causes an increase in the required total aqueous $\mathrm{Zn}$ content of two orders of magnitude to reach and establish equilibrium, and the chemical stability trends all shift towards more alkaline $\mathrm{pH}$ values. Chemical stability diagrams for the $\mathrm{Zn}$ system that incorporate ligand complexation effects exist sparingly in the literature, such as in Tay et al.,$^{35}$ which considers only $\mathrm{OH}^{-}$complexation effects on aqueous $\mathrm{Zn}$ ion availability. However, no $\mathrm{Zn}$ stability diagrams exist to predict the complexity of corrosion products shown here, nor do any works consider $\mathrm{Cl}^{-}$and $\mathrm{OH}^{-}$complexation in a $\mathrm{CO}_{3}{ }^{2-}$-containing environment, and none exist which also track such a complex system state via chemical trajectories. As shown in Fig. $4, \mathrm{ZnCO}_{3}$ remains the most readily formed corrosion product from $\mathrm{pH} 6.0$ to 7.8 when $\mathrm{Cl}^{-}$complexation is considered, followed by
$\mathrm{Zn}_{5}\left(\mathrm{CO}_{3}\right)_{2}(\mathrm{OH})_{8}$ from a $\mathrm{pH}$ of 7.8 to 10.8 , and lastly $\mathrm{Zn}(\mathrm{OH})_{2}$ (epsilon) from $\mathrm{pH} 10.2$ to 13.7. At the point of least $\mathrm{Zn}$ content requirement for formation at $\mathrm{pH} 10.2, \mathrm{Zn}_{5}\left(\mathrm{CO}_{3}\right)_{2}(\mathrm{OH})_{6}$ and $\mathrm{Zn}(\mathrm{OH})_{2}$ (epsilon) require approximately $1 \times 10^{-6} \mathrm{M}$ and $2 \times$ $10^{-6} \mathrm{M}\left[\mathrm{Zn}_{\mathrm{Tot}}\right]$. The chemical trajectories for each corrosion product are relatively similar despite considerable differences in elemental ratios required to form the range of products.

The effect of the chloride content and complexation was then re-evaluated by recalculating the chemical stability diagram for a dilute chloride concentration of $0.06 \mathrm{M}$ at fixed dissolved carbonate concentration of $5 \mathrm{mM}$, as shown in Fig. 5 . The first readily observed changes in the chemical stability trends are that the $\mathrm{ZnO}$ and $\mathrm{Zn}(\mathrm{OH})_{2}$ trends flatten in the neutral region, and the minima in zinc ion concentration required to reach equilibrium of the carbonate-/chloride-containing corrosion products shift towards $\mathrm{pH}$ of $\sim 8.5$. Under these dilute chloride conditions these minima also decrease the $\mathrm{Zn}$ ion requirement for equilibrium by half an order of magnitude. The combination of these changes causes intersection of the $\mathrm{Zn}_{5}\left(\mathrm{CO}_{3}\right)_{2}(\mathrm{OH})_{6}$ and $\mathrm{Zn}(\mathrm{OH})_{2}$ (epsilon) stability curves with the chemical trajectory trends near their minima, suggesting that formation of these phases may occur at increasingly lower $\left[\mathrm{Zn}_{\text {Tot }}\right]$ until an initial $\mathrm{pH}$ of approximately 8 in the bulk system. The experimental titration results are overlaid with the thermodynamic predictions in Fig. 5 for the $\left[\mathrm{Zn}_{\mathrm{Tot}}\right]$ of $10^{-3} \mathrm{M}$ and $10^{-6} \mathrm{M}$. For the

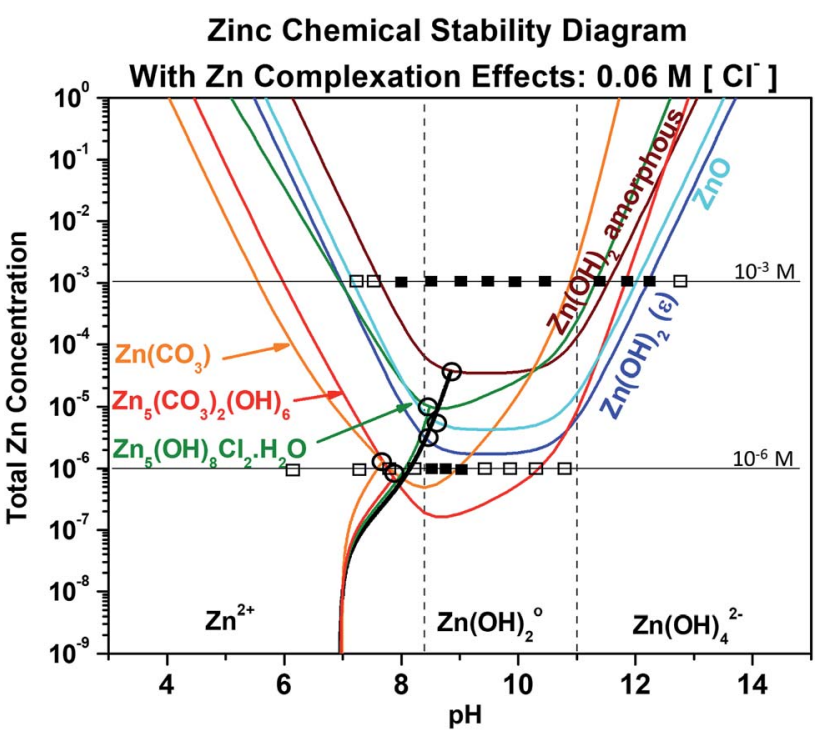

Fig. 5 Chemical stability diagram for the $\mathrm{Zn}$-water system. Relevant species are given for exposure in $\mathrm{Cl}^{-}(0.06 \mathrm{M})$ and $\mathrm{CO}_{3}{ }^{2-}(5 \mathrm{mM})$ containing environment. This diagram includes the effect of ligand complexation on the stability of the zinc compounds. Included are chemical dissolution trajectories which describe how the solution chemistry progresses to some initial condition $\left(\mathrm{pH}=7,\left[\mathrm{Zn}_{\text {Tot }}\right]=10^{-8}\right)$ to a final equilibrium condition (where the trajectory intersects an equilibrium line). The trajectory line color matches that of the compound being tracked with respect to concentration and $\mathrm{pH}$ (black corresponds to both $\mathrm{Zn}(\mathrm{OH})_{2}$ and $\mathrm{ZnO}$ due to the expense of their trajectory being the same (Table 1$)$ ). For $10^{-3} \mathrm{M}$ and $10^{-6} \mathrm{M}$ aqueous $\mathrm{Zn}$ concentration, titration data are overlaid with the model predictions, where $(\square)$ means completely solubilized and ( $\square$ ) means that solid Zn corrosion product formed. 


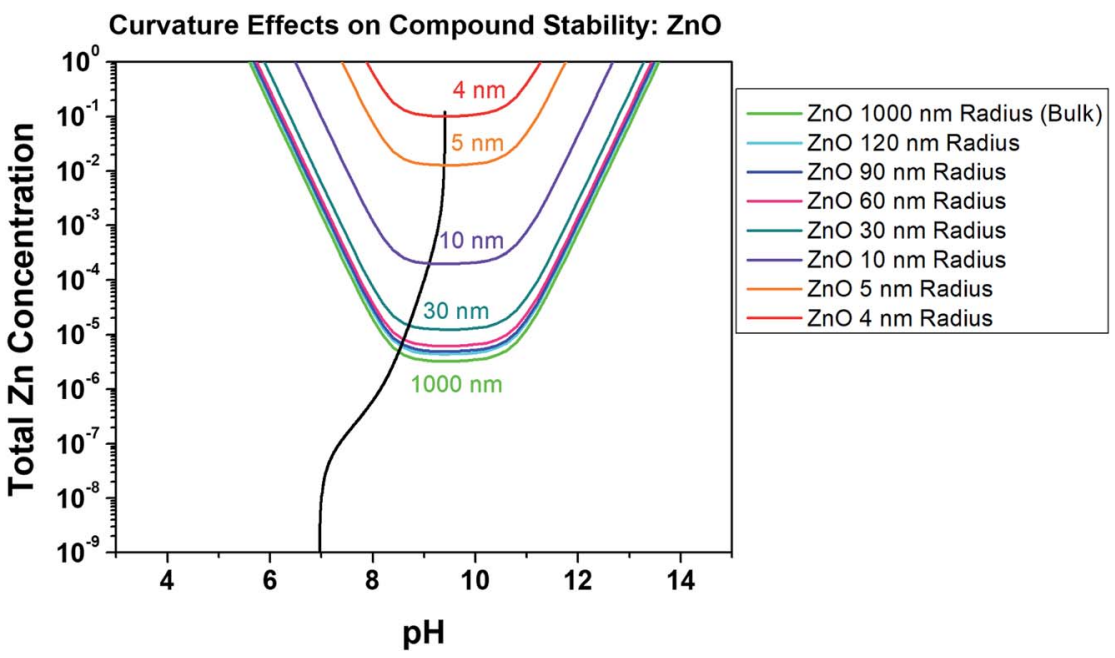

Fig. 6 Chemical stability diagram for $\mathrm{ZnO}$ at various particle radii at the nanometer scale, illustrating the effect of surface curvature on the

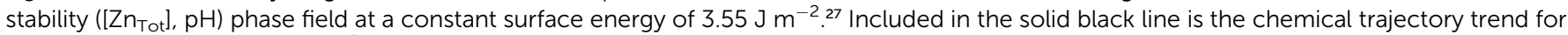
a starting $\mathrm{pH}$ of $7,\left[\mathrm{Zn}_{\mathrm{Tot}}\right]=10^{-8}$. This thermodynamic calculation assumes a constant temperature of $298 \mathrm{~K}$ and spherical capillarity effects on a (111), relaxed lattice $\mathrm{ZnO}$ surface condition. $\mathrm{A}\left[\mathrm{Cl}^{-}\right]$of $0.06 \mathrm{M}$ is considered here.

$10^{-3} \mathrm{M}$ case, these results show better correlation with thermodynamic predictions in the alkaline $\mathrm{pH}$ range than in the near-neutral/acidic region. Specifically, the $\mathrm{Zn}$ corrosion products do not form as predicted below $\mathrm{pH} \approx 8$. In the $10^{-6} \mathrm{M}$ $\left[\mathrm{Zn}_{\text {Tot }}\right]$ data, similar differences are present, namely a reduced $\mathrm{pH}$ range of solid product formation than thermodynamically predicted.

\subsection{Chemical stability as a function of complexation and curvature}

Nanoparticles of $\mathrm{ZnO}$ are being increasingly utilized in the biomedical, corrosion engineering, and energy sectors, and

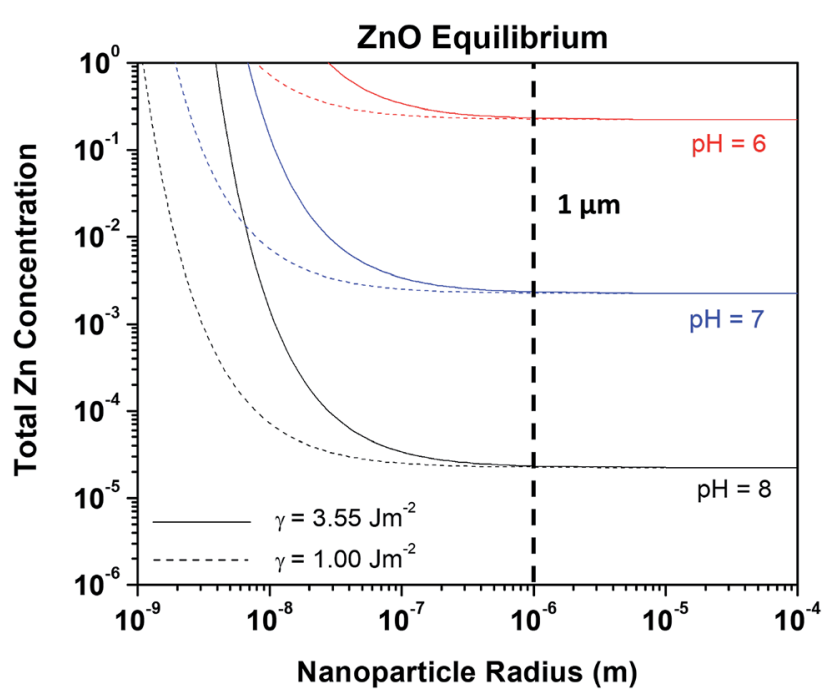

Fig. 7 Line plot demonstrating the effect of $\mathrm{ZnO}$ particle radius on the equilibrium $\left[Z n_{A q}\right]_{T o t}$ stability requirement. The effect of varying surface energy is given by the trends produced for the two different surface energy values (eqn (5)). their formulation can be both dangerous due to high reactivity and costly. ${ }^{16,36}$ For this reason, $\mathrm{ZnO}$ has been thoroughly studied in terms of production pathways, quality, and the effects of different production methods on particle size and surface reactivity/energy. ${ }^{31}$ One theoretical study found that the surface energy of $\mathrm{ZnO}$ on the relaxed (111) plane at $298 \mathrm{~K}$ remains relatively constant at $3.55 \mathrm{~J} \mathrm{~m}^{-2},{ }^{27}$ which we utilized here to evaluate the $\mathrm{Zn}_{\mathrm{aq}}$ requirement for $\mathrm{ZnO}$ nanoparticle equilibrium as a function of radius, $\mathrm{Zn}^{2+}$ and $\mathrm{pH}$. This GibbsThompson-based chemical stability prediction is shown in Fig. 6, demonstrating the increase in the required $\left[\mathrm{Zn}_{\text {Tot }}\right]$ for $\mathrm{ZnO}$ nanoparticle equilibration at increasingly small radii. Specifically, a $\mathrm{ZnO}$ nanoparticle with radius of $4 \mathrm{~nm}$ at $\mathrm{pH} 9.5$ is soluble at roughly four orders of magnitude greater $\left[\mathrm{Zn}_{\mathrm{Tot}}\right]$ in the bulk solution than is a nanoparticle having radius of $30 \mathrm{~nm}$, and therefore is less thermodynamically stable. As the $\mathrm{ZnO}$ surface energy is fixed here at a value theoretically calculated in vacuum, the effect of utilizing a different $\gamma$ value was evaluated in Fig. 7. These predictions demonstrate that there is an observable effect on the equilibrium requirement for $\mathrm{ZnO}$ nanoparticles in terms of $\left[\mathrm{Zn}_{\mathrm{Tot}}\right]$ and $\mathrm{pH}$ conditions by changing $\gamma$ from $3.55 \mathrm{~J} \mathrm{~m}^{-2}$ to $1.00 \mathrm{~J} \mathrm{~m}^{-2}$, however this effect only exists at radii less than 1 micrometer $\left(10^{-6} \mathrm{~m}\right)$. These findings are comparable to experimental findings present in the literature, as will be explored in the Discussion.

\section{Discussion}

Zinc remains a consistently utilized metal today, with ever diversifying applications pertaining to health, biotechnology, and energy. With these diverse needs comes the demand to understand $\mathrm{Zn}$ corrosion and the formation of specific oxidation products in changing electrochemical conditions and saline environments, as these changes may be either beneficial or detrimental to component performance. In studies on $\mathrm{Zn}$ - 
rich primers (ZRPs), for instance, not only are certain products such as $\mathrm{Zn}_{5}\left(\mathrm{CO}_{3}\right)_{2}(\mathrm{OH})_{6}$ known to be more passivating and protective than others, ${ }^{\mathbf{1 3}}$ but each corrosion product will also have a characteristic volume increase associated with its formation that is known to affect coating porosity, $\mathrm{Zn}$ pigment connectivity, and the electrolyte ingress necessary for pigment activation to achieve effective corrosion protection on vital alloys such as steel. ${ }^{\mathbf{1 3}, 37-43}$ Comparison of the present modeling results with experimental findings on $\mathrm{Zn}$ in the literature will enlighten the reader as to the accuracy and utility of these new developments to advance the scope of the chemical stability diagram. Furthermore, comparison will be drawn from the wide spectrum of literature on $\mathrm{ZnO}$ nanoparticle formation ${ }^{\mathbf{1 9 , 3 1 , 3 6 , 4 4}}$ to discuss the potential for utilizing the Gibbs-Thompson rederivation of the $\mathrm{ZnO}$ chemical stability diagram.

Titration results provided initial insight into the utility of the present thermodynamic calculations to predict solid Zn-based corrosion product formation in $\mathrm{NaCl}$. In order to further understand the utility of the presently developed chemical stability diagram methods, a thorough literature review will demonstrate notable experimental results and trends for the pure $\mathrm{Zn}$ system. Experimental studies demonstrate that Zn corrosion is largely dictated by anionic surface chemistry and bulk $\mathrm{pH}$ conditions, and that reaction kinetics play a significant role only in select situations, which suggests that chemical stability diagrams could be a valuable predictive tool when accurately applied to the $\mathrm{Zn}$ system..$^{\mathbf{1 2 , 3 0 , 4 5 , 4 6}} \mathrm{At} \mathrm{pH}$ lower than 5.0 or higher than 13.5, little to no corrosion product formation typically occurs on $\mathrm{Zn} .{ }^{\mathbf{1 2 , 4 7}}$ At more intermediate $\mathrm{pH}$ values, experimental results have shown that $\mathrm{Zn}$ easily forms carbonate species, as dictated by the absorption and presence of $\mathrm{CO}_{3}{ }^{2-}$ in the electrolyte. ${ }^{\mathbf{1 3 , 4 5}}$ These findings on pure $\mathrm{Zn}$ agree with alternate immersion studies on ZRPs, which find an increasing presence of $\mathrm{CO}_{3}$-containing $\mathrm{Zn}$ corrosion product formation with increased drying time (and thus increasing concentration of dissolved $\mathrm{CO}_{3}{ }^{2-}$ in the surface film). ${ }^{13,37}$ Ohtsuka and Matsuda demonstrated through use of in situ Raman spectroscopy that $\mathrm{ZnO}$ and $\mathrm{Zn}(\mathrm{OH})_{2}$ (epsilon) readily form on the $\mathrm{Zn}$ surface during dry air exposure, and as the relative humidity ( $\mathrm{RH})$ is increased to $75 \% \mathrm{Zn}_{5}\left(\mathrm{CO}_{3}\right)_{2}(\mathrm{OH})_{6}$ also forms. ${ }^{37}$ At continuous $\mathrm{RH}$ of $80 \%$ or more, only $\mathrm{Zn}_{5}(\mathrm{OH})_{8} \mathrm{Cl}_{2} \cdot \mathrm{H}_{2} \mathrm{O}$ and aqueous $\mathrm{ZnCl}_{2}^{0}$ formation occur on the $\mathrm{Zn}$ surface. ${ }^{37}$ When drying cycles are introduced intermittent to the establishment of $88 \% \mathrm{RH}$, a combination of $\mathrm{ZnO}, \mathrm{Zn}_{5}\left(\mathrm{CO}_{3}\right)_{2}(\mathrm{OH})_{6}, \mathrm{Zn}_{5}(\mathrm{OH})_{8} \mathrm{Cl}_{2} \cdot \mathrm{H}_{2} \mathrm{O}$, and aqueous $\mathrm{ZnCl}_{2}^{0}$ are found on the $\mathrm{Zn}$ surface, with the amount of $\mathrm{Zn}_{5}\left(\mathrm{CO}_{3}\right)_{2}(\mathrm{OH})_{6}$ increasing as greater drying to wetting ratio was allowed. ${ }^{37}$ Mouanga et al. and Ligier et al. also demonstrated that $\mathrm{Zn}_{5}\left(\mathrm{CO}_{3}\right)_{2}(\mathrm{OH})_{6}$ and $\mathrm{Zn}_{5}(\mathrm{OH})_{8} \mathrm{Cl}_{2} \cdot \mathrm{H}_{2} \mathrm{O}$ were the major corrosion products formed on pure $\mathrm{Zn}$ following atmospheric exposure in dilute chloride, which is supported in the literature by the known transformation of $\mathrm{Zn}(\mathrm{OH})_{2} / \mathrm{ZnO}$ to these more complex products as a function of dissolved carbonate content. ${ }^{13,48}$ In agreement with these proposed mechanisms, Marchebois et al. demonstrated that the formation of $\mathrm{ZnO}$ occurs quickly on pure $\mathrm{Zn}$ in full simulated seawater immersion, followed by the formation of increasing amounts of $\mathrm{Zn}_{5}(\mathrm{OH})_{8} \mathrm{Cl}_{2} \cdot \mathrm{H}_{2} \mathrm{O}$ with time. ${ }^{40}$ The presently developed $\mathrm{Zn}$ chemical stability diagrams predict many of these experimental results and demonstrate strong utility for the thermodynamically-dictated Zn system.

Chemical stability diagrams are based on thermodynamic stability and cannot communicate the influence of kinetics in the formation of $\mathrm{Zn}$ corrosion products. However, cross comparison of these diagrams with the extensive experimental evidence present in the literature can suggest the utility of these diagrams where stability, rather than kinetics, is dominant, and can infer where the electrochemical kinetics may be necessary to obtain the equilibrium $\mathrm{Zn}$ concentration. Fig. 5 demonstrates that during dilute chloride immersion of the $\mathrm{Zn}$ surface, the formation of any $\mathrm{Zn}$ corrosion products outside of the $\mathrm{pH}$ value range of 4.5 to 13.5 would require 1 or more moles of aqueous $\mathrm{Zn}$ content. The low probability of such a high $\mathrm{Zn}$ ion concentration being present agrees with the experimental findings showing that little to no corrosion product forms outside the $\mathrm{pH}$ range of 5.0 to $13.5 .{ }^{47}$ In dilute alkalinity, such as in the conditions which may occur where low RH is present, Fig. 5 predicts the formation of $\mathrm{Zn}(\mathrm{OH})_{2}$ (epsilon) followed by $\mathrm{ZnO}$. This prediction is in agreement with Ohtsuka and Matsuda. ${ }^{37}$ However, the dominance of $\mathrm{ZnO}$ formation with increasing exposure time suggests that $\mathrm{Zn}(\mathrm{OH})_{2}$ (epsilon) is affected more by kinetic limitations such that $\mathrm{ZnO}$ is more readily formed. Additionally, it is possible that the assumed thermodynamic variables utilized here may not accurately reflect experiment, as the conventional chemical potential for $\mathrm{NiO}$ was recently revisited using first-principle modelling. ${ }^{7}$ When $\mathrm{RH}<80 \%$ is present, $\mathrm{Zn}_{5}\left(\mathrm{CO}_{3}\right)_{2}(\mathrm{OH})_{6}$ coexists with $\mathrm{ZnO}$ and $\mathrm{Zn}(\mathrm{OH})_{2}$ in the presence of $\mathrm{NaCl}$ salt, which directly agrees with Fig. 5 at pH of 10.7 or less. The acidification of the chloride solution to achieve $\mathrm{pH}$ less than 10.1 would agree with the known effects of atmospheric $\mathrm{CO}_{2}$ aqueous absorption to form carbonic acid, known on a large scale as the ocean acidification process. ${ }^{28}$ When utilizing the chemical trajectory trends from the example starting condition of $\mathrm{pH} 7.0$, the $\mathrm{Zn}(\mathrm{OH})_{2}$ (epsilon)/ZnO formation (solid black trajectory line) would begin at more alkaline $\mathrm{pH}(8.30 / 8.55)$ than the formation of $\mathrm{Zn}_{5}\left(\mathrm{CO}_{3}\right)_{2}(\mathrm{OH})_{6}$ (solid red trajectory line) ( $\mathrm{pH} 8.00)$. Given a condition of sufficient wetting to increase $\left[\mathrm{Cl}^{-}\right]$, the $\mathrm{Zn}(\mathrm{OH})_{2}$ (epsilon), $\mathrm{ZnO}$, and $\mathrm{Zn}_{5}\left(\mathrm{CO}_{3}\right)_{2}(\mathrm{OH})_{6}$ trends would shift slightly towards more alkaline values and $\mathrm{Zn}_{5}(\mathrm{OH})_{8} \mathrm{Cl}_{2} \cdot \mathrm{H}_{2} \mathrm{O}$ formation would more readily occur (Fig. 4). These trends are also in agreement with the results of Ohtsuka and Matsuda, wherein increased $\mathrm{RH}$ caused the stabilization of aqueous $\mathrm{ZnCl}_{2}^{0}$ and $\mathrm{Zn}_{5}(\mathrm{OH})_{8} \mathrm{Cl}_{2} \cdot \mathrm{H}_{2} \mathrm{O}$ in the thin film. ${ }^{37}$ As illustrated in Fig. 1, aqueous $\mathrm{ZnCl}_{x}$ species predominate at $\mathrm{pH} 9.8$ or less in conditions of high $\left[\mathrm{Cl}^{-}\right]$, and in saturated NaCl conditions Fig. 4 would predict that $\mathrm{Zn}_{5}(\mathrm{OH})_{8^{-}}$ $\mathrm{Cl}_{2} \cdot \mathrm{H}_{2} \mathrm{O}$ stability would be reached prior to $\mathrm{Zn}(\mathrm{OH})_{2}$ (epsilon)/ $\mathrm{ZnO}$ equilibration at $\mathrm{pH} 9.0$ or less. Specifically, recalculation of these ion predominance relations demonstrates that aqueous $\mathrm{ZnCl}_{2}^{0}$ is the most abundant species when $\left[\mathrm{Cl}^{-}\right]$is between $0.7 \mathrm{M}$ and $1.2 \mathrm{M}$.

The thermodynamic predictions presented here also correlate well with long-term, controlled atmospheric exposure results on pure $\mathrm{Zn}$ where the $\left[\mathrm{Cl}^{-}\right]$and/or $\left[\mathrm{CO}_{3}{ }^{2-}\right]$ were limited. $\mathrm{Qu}$ et al. deposited dilute amounts of $\mathrm{NaCl}$ on the $\mathrm{Zn}$ surface 
and held $80 \%$ RH using purified water vapor and air for 25 hours, which resulted in the formation of $\mathrm{ZnO}$ and $\mathrm{Zn}_{5}(\mathrm{OH})_{8^{-}}$ $\mathrm{Cl}_{2} \cdot \mathrm{H}_{2} \mathrm{O} .{ }^{49}$ Svensson and Johansson performed similar experiments on pure $\mathrm{Zn}$ but for 420 hours at $70 \% \mathrm{RH}$, and only $\mathrm{Zn}_{5}(\mathrm{OH})_{8} \mathrm{Cl}_{2} \cdot \mathrm{H}_{2} \mathrm{O}$ was observed through X-ray diffraction regardless of the amount of $\mathrm{NaCl}$ deposited on the $\mathrm{Zn}$ surface prior to exposure. ${ }^{50}$ In light of the known transformation of $\mathrm{ZnO} / \mathrm{Zn}(\mathrm{OH})_{2}$ with increasing exposure time, these results agree well with Fig. 5 for the initial $\mathrm{pH}$ of 7 due to the lack of carbonate species introduced during these experiments. Specifically, these thermodynamic predictions would dictate that $\mathrm{ZnO}$ would begin to form at $\mathrm{pH}$ of 8.5 and $\left[\mathrm{Zn}_{\mathrm{aq}}\right]$ of $6 \times$ $10^{-6} \mathrm{M}$, while $\mathrm{Zn}_{5}(\mathrm{OH})_{8} \mathrm{Cl}_{2} \cdot \mathrm{H}_{2} \mathrm{O}$ formation would require higher concentration, $\left[\mathrm{Zn}_{\mathrm{aq}}\right]$ of $1 \times 10^{-5} \mathrm{M}$, at $\mathrm{pH}$ 8.5. In the case of Svensson and Johansson, additional salt deposition at $75 \% \mathrm{RH}$ would increase $\left[\mathrm{Cl}^{-}\right]$towards saturation, which would explain the dominance of the $\mathrm{Zn}_{5}(\mathrm{OH})_{8} \mathrm{Cl}_{2} \cdot \mathrm{H}_{2} \mathrm{O}$ formation; as $\left[\mathrm{Cl}^{-}\right]$increases, $\mathrm{Zn}_{5}(\mathrm{OH})_{8} \mathrm{Cl}_{2} \cdot \mathrm{H}_{2} \mathrm{O}$ becomes more stable than $\mathrm{ZnO}$ at $\mathrm{pH}$ below 10.0 as seen in the high $\left[\mathrm{Cl}^{-}\right]$case of Fig. $4 .^{50}$ Ligier et al. evaluated pure $\mathrm{Zn}$ corrosion product formation following exposure to simulated atmospheric electrolytes containing $5 \times 10^{-3} \mathrm{M} \mathrm{NaHCO}_{3} / 1 \times 10^{-3} \mathrm{H}_{2} \mathrm{O}_{2}$ and $2 \times 10^{-1} \mathrm{M}$ $\mathrm{NaCl} / 5 \times 10^{-3} \mathrm{NaHCO}_{3} / 1 \times 10^{-3} \mathrm{M} \mathrm{H}_{2} \mathrm{O}_{2}$ for 4 days, and demonstrated that the amount of $\mathrm{Zn}_{5}\left(\mathrm{CO}_{3}\right)_{2}(\mathrm{OH})_{6}$ formed on $\mathrm{Zn}$ depends on the $\left[\mathrm{Cl}^{-}\right]$concentration, as $\mathrm{Zn}_{5}(\mathrm{OH})_{8} \mathrm{Cl}_{2} \cdot \mathrm{H}_{2} \mathrm{O}$ formation quickly dominates. ${ }^{13}$ These results do not correlate well with the dilute $\left[\mathrm{Cl}^{-}\right]$or saturated $\left[\mathrm{Cl}^{-}\right]$prediction shown in Fig. 4 and 5 for an initial $\mathrm{pH}$ of 7 , suggesting that kinetic limitations may have more effect in $\mathrm{Zn}_{5}\left(\mathrm{CO}_{3}\right)_{2}(\mathrm{OH})_{6}$ than in $\mathrm{Zn}_{5}(\mathrm{OH})_{8} \mathrm{Cl}_{2} \cdot \mathrm{H}_{2} \mathrm{O}$ formation; perhaps with a difference in $\mathrm{CO}_{3}{ }^{2-} / \mathrm{Cl}^{-}$diffusivity. None of the aforementioned atmospheric exposures resulted in the formation of $\mathrm{ZnCO}_{3}$, despite this corrosion product being the most stable from $\mathrm{pH} 4.0$ to 7.7 in dilute chloride and from pH 5.7 to 7.8 in saturated chloride conditions (Fig. 4 and 5). However, the 13-16 year marine exposures conducted on pure $\mathrm{Zn}$ by de la Fuente et al. demonstrate $\mathrm{ZnO}, \mathrm{ZnCO}_{3}$, and $\mathrm{Zn}_{5}(\mathrm{OH})_{8} \mathrm{Cl}_{2} \cdot \mathrm{H}_{2} \mathrm{O}$ formation, suggesting that either the previous experiments did not reach sufficiently low $\mathrm{pH}$ or that $\mathrm{ZnCO}_{3}$ has slow formation kinetics. ${ }^{51}$

The present diagrams focus solely on a chloride-based saline environment with equilibrium carbonate concentration of $5 \mathrm{mM}$ (adjustable to consider more dilute cases), which does not include the effects of impurities present in the electrolyte such as sulfur, less common corrosion product formation, or changing temperature (all calculations done at $25^{\circ} \mathrm{C}$ ) (for more detail on the assumptions see the ESI $\dagger$ ). However, further advancement of these diagrams to incorporate such effects will prove useful for predicting $\mathrm{Zn}$ corrosion in unique settings, such as for the design of effective cathodic protection systems. Modern developments in the use of $\mathrm{ZnO}$ have produced a much wider spectrum of uses for this material, however, in which the chemical stability diagram based on the Gibbs-Thompson rederivation may also prove useful to predict performance.

Zinc oxide has the unique duality of a large direct band gap and the ability to form nanostructures, making the applications for this material far-reaching: ranging from drug delivery and cancer therapy to piezoelectric power generation and spintronics. ${ }^{31}$ Considerable research has been dedicated to expanding the growth and production procedures as well as to discover new applications for $\mathrm{ZnO}$, especially when used in the form of nanoparticles and nanorods. ${ }^{31,35,44}$ Such research is motivated by the strong tunability of the size, shape, and morphology of $\mathrm{ZnO}$ crystals in solutions such as $\mathrm{ZnAc}_{2}{ }^{31,35}$ Specifically, in this solution the ZnO size, density, growth uniformity, and crystal morphology may be tuned via control of the $\mathrm{ZnAc}_{2}$ concentration and the solution $\mathrm{pH}$ through addition or subtraction of $\mathrm{NH}_{4} \mathrm{OH} .{ }^{31}$ Despite the typical use of organic solutions to contain the $\mathrm{ZnO}$ formation reactions, common $\mathrm{ZnO}$ growth trends exist that enable correlation with the present thermodynamic analysis in aqueous Cl-based environment.

Fig. 6 demonstrates the concept of the curvature-dependent chemical stability diagram derivation in $\mathrm{NaCl}$ for comparison to the bulk thermodynamic predictions shown in Fig. 3-5, demonstrating that as much as 5 orders of magnitude increase in aqueous $\mathrm{Zn}$ concentration is necessary for $\mathrm{ZnO}$ to be thermodynamically stable in Cl-containing environment at increasing nanoscale size, from the bulk (greater than 1 micrometer) to $4 \mathrm{~nm}$ particle radius. These predictions also demonstrate that the dependence of $\mathrm{ZnO}$ solubility on surface curvature is greater than the effect of $\left[\mathrm{Cl}^{-}\right]$complexation, which is supported by the results of $\mathrm{ZnO}$ synthesis studies utilizing various $\mathrm{ZnO}$ precipitation methods in non-chloride-containing solutions. Moazzen et al. observed that the average $\mathrm{ZnO}$ nanoparticle size produced in $\mathrm{Zn}$ acetate dihydrate + sodium hydroxide solution increased as the ratio of $\mathrm{Zn}$ acetate dihydrate to sodium hydroxide was decreased from 1:1 (20 nm ZnO particle size) to $1: 4$ (36 $\mathrm{nm} \mathrm{ZnO}$ particle size).$^{52}$ When hydrothermally growing $\mathrm{ZnO}$ nanorods in $\mathrm{Zn}$ acetate and ammonia, Tay et al. observed increasingly smaller, denser $\mathrm{ZnO}$ nanorods forming as the $\mathrm{Zn}$ acetate concentration was increased for a given concentration of ammonia following three hours at 370 K. ${ }^{35}$ Tay et al. utilized curvature relations based in nucleation theory as well as a basic Zn chemical stability diagram prediction to support and explain these findings, which arrived at similar conclusions as seen here. ${ }^{35}$ Recent work in lead-based systems has demonstrated utility of curvature-based solubility relationships for determining nanoparticle formation as well. ${ }^{53}$ These results also illuminate the effect of surface energy on the stability of capillary-affected surfaces. Fig. 7 illustrates that larger concentrations of aqueous $\mathrm{Zn}$ are indeed for surfaces with higher surface energy. The curvature-dependent derivation illustrated here may easily be expanded to offer further insight into mechanisms underlying $\mathrm{ZnO}$ growth in more favorable and economically viable media (out of the scope of the present work), especially as the solubility constants necessary for such mathematical constructs are increasingly available for the $\mathrm{Zn}$ species of interest to $\mathrm{ZnO}$ growth. ${ }^{21,22,54,55}$

\section{Conclusion}

The chemical stability diagram concept has been advanced within the present work to encompass (1) "actual" solubility through accounting for all known species complexes; (2) chemical trajectories based on complex elemental ratios and 
present species which predict $\mathrm{pH}$ and $\mathbf{M}^{n+}$ conditions where specific corrosion products are expected to be in equilibrium with specific compounds, as well as the $\mathbf{M}^{n+}$ and $\mathrm{pH}$ ranges where these products are soluble, and (3) the dependence of solubility on surface curvature relevant to the prediction of nanoscale growth and morphology. The utility of this method was demonstrated for the corroding $\mathrm{Zn}$ system on the bulk scale, and for the $\mathrm{ZnO}$ system at the nanoscale in $\mathrm{NaCl}$ environment. These thermodynamic bulk scale predictions correlate relatively well with experiment for the $\mathrm{Zn}$ system in $\mathrm{NaCl}$ where reaction kinetics are likely to have a limited role, and suggest that the chemical stability diagram method should continue to be advanced for more accurate understanding of reaction trends in technologically relevant metals and corrosion systems.

\section{Data availability statement}

All thermodynamic constants utilized in the present work may be found in raw form in the references provided, or derived from the raw form using methods described in the ESI. $\dagger$ Calculations generated during this study are available in an open access data repository, which can be accessed at DOI: 10.17605/OSF.IO/Y39U6.

\section{Author contributions}

All authors contributed to the derivation and construction of these chemical stability diagrams, as well as to the structure and composition of this manuscript. M. E. M. provided literature review of Zn corrosion and drafted the paper. R. J. S. Jr provided literature review of publications utilizing speciation and/or chemical stability methods, created the graphical abstract, and modified the manuscript. J. R. S. reviewed, edited, and modified the manuscript.

\section{Conflicts of interest}

The authors declare no competing interests.

\section{Acknowledgements}

The authors are grateful for the financial support and contribution of the United States Office of Naval Research [Award \# N000141512491] under the direction of Dr Airan Perez, the United States Office of the Undersecretary of Defense Corrosion University Pilot Program [Award \# FA7000-14-2-0010] under the direction of Mr Daniel Dunmire, and the National Science Foundation [Award \# NSF DMR \#1309999].

\section{References}

1 F. M. Toma, J. K. Cooper, V. Kunzelmann, M. T. McDowell, J. Yu, D. M. Larson, N. J. Borys, C. Abelyan, J. W. Beeman, K. M. Yu, J. Yang, L. Chen, M. R. Shaner, J. Spurgeon, F. A. Houle, K. A. Persson and I. D. Sharp, Nat. Commun., 2016, 7, 1-11.
2 M. Schuisky and A. Harsta, J. Electrochem. Soc., 1998, 145, 4234-4239.

3 D. G. Kinniburgh and D. M. Cooper, Environ. Sci. Technol., 2004, 38, 3641-3648.

4 J. D. Hem, Hydrol. Sci. J., 1960, 5, 45-53.

5 H. L. Bohn, R. A. Myer and G. A. O'Connor, in Soil Chemistry, John Wiley \& Sons, Inc., New York, 3rd edn, 2001, pp. 201206.

6 M. Pourbaix, Atlas of Electrochemical Equilibria in Aqueous Solutions, National Association of Corrosion Engineers, 1974.

7 L. F. Huang, M. J. Hutchison, R. J. Santucci, J. R. Scully and J. M. Rondinelli, J. Phys. Chem. C, 2017, 121, 9782-9789.

8 R. J. Santucci, M. E. McMahon and J. R. Scully, npj Mater. Degrad., 2018, 2, 1.

9 P. Plagemann, J. Weise and A. Zockoll, Prog. Org. Coat., 2013, 76, 616-625.

10 J. Lin, D. Battocchi and G. P. Bierwagen, Corrosion, 2017, 73, 408-416.

11 W. Xu, N. Birbilis, G. Sha, Y. Wang, J. E. Daniels, Y. Xiao and M. Ferry, Nat. Mater., 2015, 14, 1229-1235.

12 X. G. Zhang, Corrosion and Electrochemistry of Zinc, Plenum Press, New York, 1st edn, 1996.

13 V. Ligier, M. Wéry, J.-Y. Hihn, J. Faucheu and M. Tachez, Corros. Sci., 1999, 41, 1139-1164.

14 A. A. Bagabas, R. M. Mohamed, M. F. A. Aboud, M. M. M. Mostafa, A. S. Alshammari and Z. A. Al-Othman, US Pat., 8361324, 2013.

15 K. S. Suganthi, Flexible Printed Electron., 2018, 3, 1-11.

16 H. Agarwal, S. Venkat Kumar and S. Rajeshkumar, Resour.Effic. Technol., 2017, 3, 406-413.

17 W. Salem, D. R. Leitner, F. G. Zingl, G. Schratter, R. Prassl, W. Goessler, J. Reidl and S. Schild, Int. J. Med. Microbiol., 2015, 305, 85-95.

18 P. K. Mishra, H. Mishra, A. Ekielski, S. Talegaonkar and B. Vaidya, Drug Discovery Today, 2017, 22, 1825-1834.

19 A. Król, P. Pomastowski, K. Rafińska, V. Railean-Plugaru and B. Buszewski, Adv. Colloid Interface Sci., 2017, 249, 37-52.

20 F. Verbakel, S. C. J. Meskers and R. A. J. Janssen, J. Appl. Phys., 2007, 102, 083701.

21 S. Hagemann, Entwicklung eines thermodynamischen Modells für Zink, Blei und Cadmium in salinaren Lösungen, Gesellschaft für Anlagen- und Reaktorsicherheit, (GRS) $\mathrm{mbH}$, Berlin, 1st edn, 2012.

22 G. S. James, Lange's Handbook of Chemistry, New York, 17th edn, 2017.

23 B. E. Conway, Electrochemical Data, Elsevier, Houston, 1952.

24 K. J. Kim, P. B. Kreider, C. Choi, C. H. Chang and H. G. Ahn, RSC Adv., 2013, 3, 12702-12710.

25 C. H. Choi, J. B. Levin and C. H. Chang, CrystEngComm, 2016, 18, 8645-8652.

26 S. E. A. Sharaf El-Deen, S. I. Moussa, Z. A. Mekawy, M. K. K. Shehata, S. A. Sadeek and H. H. Someda, Radiochim. Acta, 2017, 105, 43-55.

27 C. Tang, M. J. S. Spencer and A. S. Barnard, Phys. Chem. Chem. Phys., 2014, 16, 22139-22144. 
28 S. E. Manahan, Environmental Chemistry, CRC Press, New York, 8th edn, 2005.

29 I. Odnevall Wallinder and C. Leygraf, Corrosion, 2017, 73, 1060-1077.

30 S. Thomas, N. Birbilis, M. S. Venkatraman and I. S. Cole, Corrosion, 2012, 68, 015009.

31 Z. C. Feng, Handbook of Zinc Oxide and Related Materials: Volume 1, Materials, CRC Press, New York, 2013.

32 P. Volovitch, C. Allely and K. Ogle, Corros. Sci., 2009, 51, 1251-1262.

33 M. Bockelmann, L. Reining, U. Kunz and T. Turek, Electrochim. Acta, 2017, 237, 276-298.

34 S. Thomas, N. Birbilis, M. S. Venkatraman and I. S. Cole, Corros. Sci., 2013, 69, 11-22.

35 C. B. Tay, S. J. Chua and K. P. Loh, J. Cryst. Growth, 2009, 311, 1278-1284.

36 R. Brayner, S. A. Dahoumane, C. Yéprémian, C. Djediat, M. Meyer, A. Couté and F. Fiévet, Langmuir, 2010, 26, 6522-6528.

37 T. Ohtsuka and M. Matsuda, Corrosion, 2003, 59, 407-413.

38 O. Ø. Knudsen, U. Steinsmo and M. Bjordal, Prog. Org. Coat., 2005, 54, 224-229.

39 H. Marchebois, S. Joiret, C. Savall, J. Bernard and S. Touzain, Surf. Coat. Technol., 2002, 157, 151-161.

$40 \mathrm{H}$. Marchebois, C. Savall, J. Bernard and S. Touzain, Electrochim. Acta, 2004, 49, 2945-2954.

41 S. Feliu, M. Morcillo and S. Feliu, Corrosion, 2001, 57, 591597.
42 S. J. Feliu, R. Barajas, J. M. Bastidas, M. Morcillo and S. Feliu, Electrochem. Impedance Anal. ans Interpret. ASTM STP 1188, 1993, pp. 438-449.

43 E. Diler, B. Rouvellou, S. Rioual, B. Lescop, G. Nguyen Vien and D. Thierry, Corros. Sci., 2014, 87, 111-117.

44 E. A. Meulenkamp, J. Phys. Chem. B, 1998, 102, 5566-5572.

45 T. E. Graedel, J. Electrochem. Soc., 1989, 136, 193-203.

46 I. Suzuki, Corros. Sci., 1985, 25, 1029-1034.

47 B. E. Roetheli, G. L. Cox and W. B. Littreal, Met. Alloys, 1932, 3, 73-76.

48 M. Mouanga, P. Berçot and J. Y. Rauch, Corros. Sci., 2010, 52, 3984-3992.

49 Q. Qu, C. Yan, Y. Wan and C. Cao, Corros. Sci., 2002, 44, 2789-2803.

50 J. E. Svensson and L. G. Johansson, Corros. Sci., 1993, 34, 721-740.

51 D. de la Fuente, J. G. Castano and M. Morcillo, Corros. Sci., 2006, 49, 1420-1436.

52 M. A. M. Moazzen, S. M. Borghei and F. Taleshi, Appl. Nanosci., 2013, 3, 295-302.

53 C. Dai, J. Zhao, D. E. Giammar, J. D. Pasteris, X. Zuo and Y. Hu, ACS Earth Space Chem., 2018, 2, 869-877.

54 A. E. Martell and R. M. Smith, Critical Stability Constants, Plenum Press, New York, 6th edn, 1989.

55 R. Fernandez-Prini, A. H. Harvey and D. A. Palmer, Aqueous Systems at Elevated Temperatures and Pressures, Elsevier, New York, 2004. 